\title{
THE POSSIBILITY OF DISPOSING OF SPENT COFFEE GROUND WITH ENERGY RECYCLING
}

\author{
Tomasz Ciesielczuk' ${ }^{1}$ Urszula Karwaczyńska' ${ }^{1}$, Monika Sporek \\ 1 Faculty of Natural Sciences and Technology, Opole University, Oleska 48, 45-052 Opole, Poland, e-mail: \\ tciesielczuk@uni.opole.pl; ukar@uni.opole.pl; mebis@uni.opole.pl
}

Received: 2015.07.12

Accepted: 2015.08.31

Published: 2015.10.01

\begin{abstract}
The current policy of waste management requires, above all, a gradual reduction of waste amount and, to a larger extent, forces us to seek new methods of waste disposal. Recycling the energy contained in biomass waste is a more and more universally applied method of thermal converting. Biomass combustion allows saving fossil fuels which fits into sustainable development. This paper checks the possibility of using spent coffee ground (SCG) in energy recycling using a combustion process. This particular biomass type up to now has not been widely examined, which inclines to consider its usage as a potential additive to alternative fuels. In the study, we examined the quality of fuel, which was in a form of briquette, made of beech shavings with 10 and $25 \%$ of post-exploitation waste obtained during the process of coffee infusion. This waste, if fresh, is distinguished by its high hydration. However, after drying it may constitute a valuable additive to alternative fuels. It increases the calorific value of fuel and reduces briquettes' hardness what contributes to reducing resistance of conveying screw in stoves.
\end{abstract}

Keywords: biomass; spent coffee ground; energy recovery; alternative fuel.

\section{INTRODUCTION}

At present, in Poland, the biggest amount of solid municipal waste is dealt by disposing of it. Due to the fact that landfills are more and more filled up and there are difficulties in finding new ones it is vital to reduce the amount of waste on one side and to collect selectively on the other side what allows us to recycle from the waste. Biodegradable fraction is especially worth considering. This municipal waste fraction can constitute a valuable source of organic matter and could be used to fertilize processes after the composting process. Selective collection of this waste fraction at the source gives the opportunity of not only directing it to composting processes or biogas production but also to direct usage as an alternative fuel. It especially concerns biodegradable fraction separated from the municipal waste flow, combustible fraction in order to recycle energy contained in the waste, which is more often the method used of its neutralizing [Walaszek and Dudzinska 2007]. Municipal waste content depends, to a large extent, on the type of housing where it's made (urban or country) and on the season (summer, winter). The extent of society's ecological education has a considerable impact on waste content. The knowledge is expressed by sorting the waste according to its type in the collecting place. In Polish conditions the calorific value of waste is slightly lower in comparison to waste in other European countries due to a lesser amount of plastic. However, a large amount of waste and its significant calorific value and its negative impact on landfill sites (effluent, greenhouse gases), on the other hand, causes that combustion combined with energy recycling to become a more rational and economically justified way for its recycling. Nevertheless, the basic condition is to minimize the dangers of the combustion process for the surroundings and subsequent efficient purification of exhaust gases as well as recycling ashes and slag. 
One of the cutting edge technologies of the municipal waste management is its processing of fuel using numerous technologies mainly based on grinding, mechanical segregation, drying, hygenisation and subsequently granulating or briquetting. Industrial or agricultural waste (e.g.: after harvesting waste), especially timber industry waste can be directly used as a cheap alternative fuel, especially in rural areas [Chau et al. 2009, Domanska 2008, Hasan et al. 2009, Yan et al. 2006]. Wood waste in a form of wood chips can be used not only in the process of combustion, but also in the gasification creating process gas used as a fuel [Erlich et al. 2006; Gołuchowska et al 2015]. Also weed biomass can be used as an energy source, due to good calorific value [Ciesielczuk et al. 2014].

Wood waste in a form of shavings and grinding dust subjected to pelleting or briquetting are valuable and more and more commonly used as fuel - not only in households but also in small companies, and even in big plants heating production halls [Purohit et al. 2006]. This fuel is a universal product characterized by its ash ingredient at the level of $0.8-1.5 \%$, easily flammable, and its relatively high calorific value, compared to low quality coal. Any biomass originating from industry, agriculture or even households can be briquetted or pelleted. There are high hopes for using biomass to energy cogeneration in ORC and EFGT [Kautz and Hansen 2007]. The aim of this thesis explores the possibility of using spent coffee ground as an addition to wood biomass as an additive to solid alternative fuel. Annual coffee consumption in Poland is constantly increasing and is currently at $3 \mathrm{~kg} / \mathrm{M}$. It is an amount that is a few times lower in comparison to Scandinavian countries [Dudek 2005]. Due to a scanty amount of spent waste submitted to composting or methane fermentation, in equivalence to dry mass it gives approximately 115 thousand $\mathrm{Mg}$ of waste to landfills. It is $0.1 \%$ of annual hard bituminous coal extraction in Poland, which weighs in favour of using this waste to recycled energy production, which is a part of the current energy policy in Poland and Europe attempting to reduce fossil fuel usage. Using SCG as a component to alternative fuel production in a form of briquettes would allow the savings of about $89900 \mathrm{Mg}$ of coal each year.

Different biodegradable waste can be neutralized in a way of recycling its energy by subjecting it to pyrolysis or it can be used to activate carbon production or other types of sorbents used to improve the quality of water and air [Boonamnuayvitaya et al 2005, Masek et al 2008, Oliveira et al 2008, Orozco et al 2008]. When SCG undergoes the extraction process and then the obtained eluent is submitted to transesterification it can be used as a high quality biodiesel [Kondamudi et al 2008]. One of the most interesting solutions is applying supercritical $\mathrm{CO}_{2}$ to fatty acids extracted from used coffee in order to produce liquid fuels, e.g. biodiesel [Couto et al 2009]. All those processes and technologies are aimed to limit the usage of non-renewable energy sources among which the most prominent are petroleum and coal (meeting respectively $35 \%$ and $25.3 \%$ of the world's demand for primary energy) [Heinimo 2009]. Mankind is still trying to restrict the demand for mining fossil fuels in favour of renewable sources. Waste biomass constitutes a valuable energy source. It has numerous values. It is made in nearly every part of the Earth. There is no need for professional know how or expensive technologies. Moreover, in contrast to other renewable energy sources, in our weather conditions it can be even more competitive to coal with respect to the economy. Therefore, technologies are making it easier to recycle energy from biomass and it is getting more and more popular.

\section{LEGAL BASIS}

The legal basis concerning also waste management in Poland is the act of 13 September 2006 (Journal of Laws of the Republic of Poland 2013 item 1399 as amended). It is regulated in a special way determining mass limitations of biodegradable waste disposals of 50, and 35\% from 2013 and 2020, respectively in relation to the base year of 1995. Limiting disposals of 114 thousand $\mathrm{Mg}$ of dry mass SCG (in a hydrated state this mass is 191.4 thousand Mg.) annually is a conclusion contributing to attaining the appointed limits. The definition of biomass is included in the Environment Ministry order on 20 December 2005 about the emission standards from installation (Journal of Laws of the Republic of Poland No 260 issue 2181). According to the aforementioned order biomass is a product completely or partially consisting of plant which derives from agriculture, forestry, which is combusted in order to recycle its energy. Agriculture, forestry and plant waste derived from the food industry is also consid- 
ered biomass. According to these directives wood is also considered as biomass. However, wood waste covered or soaked with preservatives is not regarded as biomass according to the aforementioned order. What is more, biomass is defined in the Ministry of Economy's order from $19^{\text {th }}$ December 2005 in a detailed scope of required obligations for obtaining and putting forward to dismiss certificates of origin, substitute charge payments, and the purchase of electricity and heat made from renewable energy (Journal of Laws of the Republic of Poland No 261 issue 2187 as amended). According to this order biomass is defined as: a solid or liquid substance originating from plants or animals, which is biodegradable and which originates from products, waste from forestry and agriculture and some other biodegradable waste. Using spent coffee ground (SCG) as an alternative fuel is in accordance with the European Committee for Standardization [Alakangas et al 2006].

\section{MATERIALS AND METHODS}

In this paper we analyzed the possibilities of neutralizing spent coffee ground (SCG) which is left from coffee made in coffee makers under pressure 15 bar. The waste underwent drying in room temperature and in a dry environment was mixed with grinding dust, originating from beech wood processing. SCG additive waste was 10 and $25 \%$ $(\mathrm{m} / \mathrm{m})$ (Figures 1-3). The analysis of organic matter content was measured as a loss of ignition at $550^{\circ} \mathrm{C}$, according to standards BN-88/9103-07 and SS187171. The calorific value analysis consisted of: untreated grinded dust used for briquette production - beech wood, mixture of beech wood dust with 10 and $25 \%$ part of spent coffee ground, and spent coffee ground itself. The analysis was made using a calorimetric device KL-10 according to method described in PN-81/G-04513. Humidity analysis was carried out using a weigh method. Then the mixture underwent cold briquetting using the briquetting machine Hocker Polytechnik and a 120 bar pressure without any other additives [Kaliyan and Morey 2010].

\section{RESULTS AND DISCUSSION}

The amount of producers of fuels in the form of pellets and briquettes are growing in parallel with the increasing range of ovens diversified according to its power and constructed specifically for this fuel. Pellets and briquettes made under pressure have a lot of merits. First of all, they do not absorb humidity from the air even during its storage in a place with a relative humidity of $85 \%$ [Singh 2004]. However, using SCG as an additive causes some difficulties. The main restraining factor is the high humidity of waste (Table.1) prevented from pelleting or briquetting. Nevertheless, it appears that SCG easily gives back water and after 24 hours it takes on air dried state under the condition of keeping the same room temperature and enabling air change. Drying process can be conducted on the open air conditions for energy saving.

The analysis showed minimal differences in SCG quality obtained from pressure (15 bars) and non-pressure extraction. It mainly concerns temporal and total moisture which depends on the extraction used and on the content of substances extractable by petroleum ether. About 50\% lower content of extracting substances from petroleum ether in case of pressure extraction proves increased going compounds extracted to solution. In the paper, the density of the obtained briquettes was compared with those made of only beach wood waste. High briquettes hardness is on the one hand a desired feature while storing fuel in

Table 1. General characteristic of spent coffee ground waste obtained during pressure and non-pressure coffee extraction (SD value in brackets)

\begin{tabular}{|c|l|c|c|}
\hline No. & \multicolumn{1}{|c|}{ Parameter } & SCG 1 bar & SCG 15 bar \\
\hline 1. & Reaction $(\mathrm{pH})$ & $6.08(0.02)$ & $5.87(0.01)$ \\
\hline 2. & Temporal moisture [\%] & $72.02(0.18)$ & $59.98(0.36)$ \\
\hline 3. & Total moisture content [\%] & $73.09(0.15)$ & $61.94(0.31)$ \\
\hline 3. & Organic matter [\% dw] & $98.93(0.03)$ & $98.40(0.03)$ \\
\hline 4. & Ash content [\%] & $1.07(0.03)$ & $1.60(0.03)$ \\
\hline 5. & Bulk density $\left[\mathrm{g} / \mathrm{dm}^{3}\right]$ & $313.1(3.6)$ & $315.8(4.2)$ \\
\hline 6. & Substances extracted by petroleum ether $[\mathrm{mg} / \mathrm{kg} \mathrm{dw}]$ & $8.45(0.32)$ & $4.42(0.01)$ \\
\hline
\end{tabular}




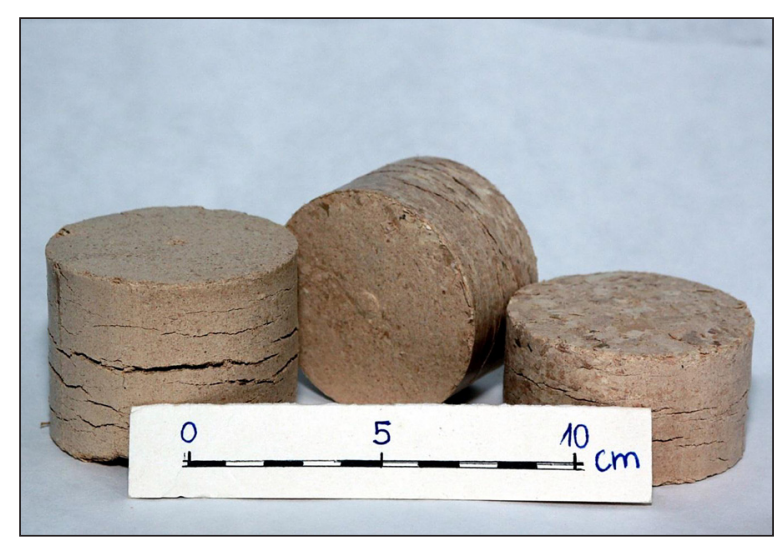

Figure 1. Briquettes made of beech wood waste

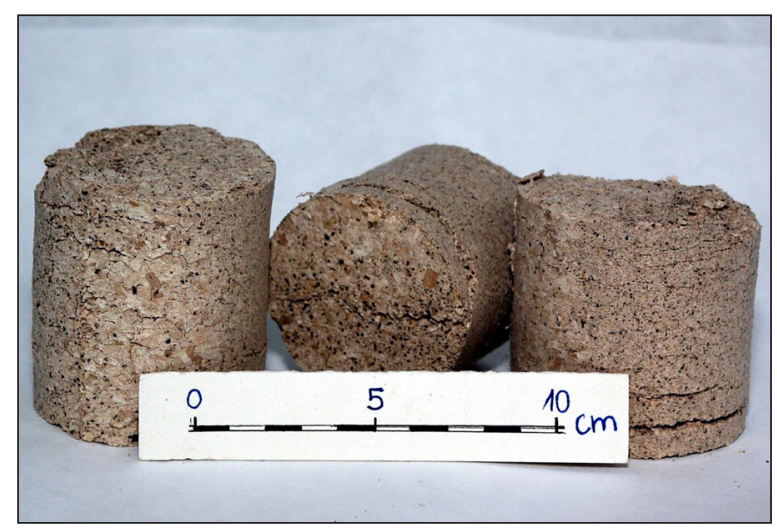

Figure 2. Briquettes made of the beech wood waste with $10 \%$ SCG addition

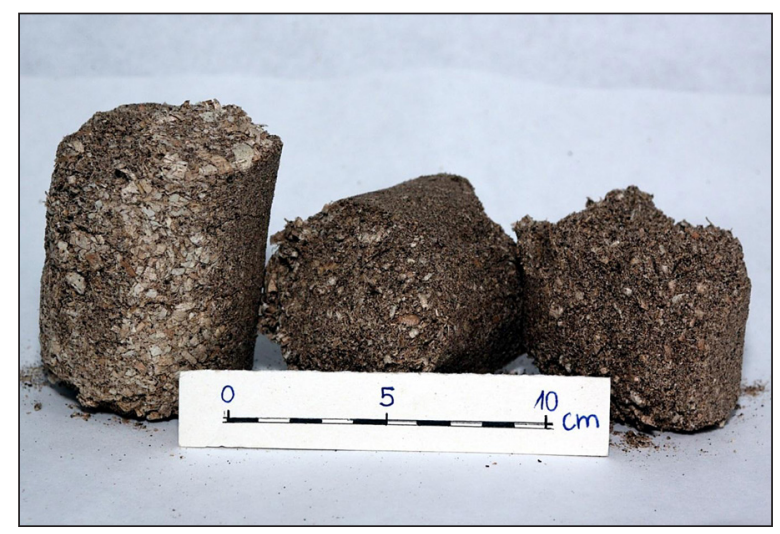

Figure 3. Briquettes made of the beech wood waste with $25 \%$ SCG addition

heaps or pellets, but it can cause increased resistance while conveying the fuel to boiler by conveying screw. A product with 10 and $25 \%$ addition of SCG was characterized by lower density, lower hardness and uneven surface of natural fracture in comparison to a product made without any additions (Table 2., Figure 1). Lower density of the obtained briquettes is an effect of lower pressure of sawdust pressing obtained during the work of the condensing unit. Pressure for all samples was set on 120 bar but that this pressure could not be reached by the briquetter due to fat content and too low friction for good compression of material.

Even though the pressure was 120 bars, obtained during briquetting values were lower and were $80-90$ bars for briquettes with $10 \%$ addition and $25-35 \%$ bars for briquettes with $25 \%$ SCG addition. It is an effect of increased fat and on account of this lesser friction during the final phase of briquettes compacting in a condensing unit (Figures 2-3). Such a low working pressure causes briquettes destruction during storage. Briquettes with SCG were less resilient and deformed while leaving the briquetting machine, increasing its diameter by $5 \%$.

Beech wood calorific values are high, nevertheless SCG addition is making it even higher (Table 2) [Obernberger and Thek 2004]. Even an addition of $10 \%$ increases the product calorific value by $1.86 \%$ and a $25 \%$ addition by $8.26 \%$ in comparison to the heat from beech wood. The examined briquettes in this regard can be compared to lesser quality hard coal. The calorific value of hard bituminous coal oscillates in quite a wide range between $16.7 \mathrm{MJ} / \mathrm{kg}$ and $32.7 \mathrm{MJ} / \mathrm{kg}$. In the case of brown coal (lignite) the same parameter is much lower, that is between 8.5-16.6 $\mathrm{MJ} / \mathrm{kg}$ (Table 3). Wood is a biological fuel (biomass) which renews annually. Newly cut trees contain $40-50 \%$ water and have low calorific value of $12.5-14.6 \mathrm{MJ} / \mathrm{kg}$. Due to environmental protection only wood waste are destined to firing (shavings, sawdust, wood chips) or special species are grown which grow fast and are destined to co combustion. Straw and plant waste is a fuel with a smaller calorific value. However, due to its high increase in mass it is a valuable renewable fuel. Its calorific value oscillates between 9.0 to $14 \mathrm{MJ} / \mathrm{kg}$.

On account of current trends regarding fuel market structure, the amount of biomass produced for energy is increasing and in Poland it was 198.4PJ per stored energy in 2008 [Domanska 2009]. Keeping average annual coffee consumption in mind and assuming that the waste left after coffee making is not recycled, it appears that we waste about 2.3 PJ of energy each year.

Nevertheless, it has to be taken into account that scattered firing solid fuels systems even in the form of biomass can be a factor deteriorating the air due to the emission of huge amounts of dust PM 2.5 [Wang et al 2007]. This dust contains smaller amounts of benzene and PAH and higher levels of heavy metals in comparison to dust 
Table 2. Basic briquettes characteristic made of pure beech wood in comparison to those with 10 and $25 \%$ of $\mathrm{SCG}$ (SD value in brackets) $\mathrm{n}=3$

\begin{tabular}{|l|c|c|c|c|}
\hline \multicolumn{1}{|c|}{ Parameter } & Pure beech wood & $10 \%$ & $25 \%$ & DIN 51731 \\
\hline Organic matter [\%] & $99.6(0.07)$ & $99.4(0.11)$ & $99.3(0.10)$ & 0150 \\
\hline Ash [\%] & 0.37 & 0.57 & 0.68 & $<1.5$ \\
\hline Proper density $\left[\mathrm{g} / \mathrm{cm}^{3}\right]$ & $0.95(0,02)$ & $0.83(0.02)$ & $0.73(0.01)$ & $1.0-1.4$ \\
\hline Calorific value $[\mathrm{MJ} / \mathrm{kg}]$ & $18.77(0.18)$ & $19.12(0.07)$ & $20.32(0.11)$ & 17.5 \\
\hline
\end{tabular}

Table 3. Solid fuels parameters and basic composition [Kordylewski 1999]

\begin{tabular}{|l|c|c|c|c|}
\hline \multicolumn{1}{|c|}{ Parameter } & Unit & Hard coal & Brown coal & Peat \\
\hline Calorific value & MJ/kg & $16.7-32.7$ & $8.5-16.6$ & $11-16$ \\
\hline Humidity & $\%$ & $5-30$ & $15-55$ & $20-40$ \\
\hline Ash & $\%$ d.w. & $5-40$ & $10-35$ & 40 \\
\hline Carbon & $\%$ C d.w. & $65-85$ & $66-73$ & 58 \\
\hline Hydrogen & $\%$ H d.w. & $4.7-5.9$ & $5-7$ & 5.5 \\
\hline Nitrogen & \% N d.w. & $1.4-3$ & $0.7-1.5$ & 1.8 \\
\hline Sulphur & \% S d.w. & $0.8-2$ & $0.7-7$ & 0.2 \\
\hline
\end{tabular}

originating from road traffic from motor vehicles [Olsson and Kjallstrand 2004, Mazzoli-Rocha et al 2008]. At the same time large amounts of organic matter like: alkanes, phenols, carboxylic acids, $\mathrm{PCDD} / \mathrm{F}$ and others are emitted into the air [Shih et al. 2008]. The amount of emitted organic carbon can even reach $2.1 \mathrm{~g} / \mathrm{kg}$ combusted fuel [Wang et al 2009]. Drying SCG can also be challenging. Therefore, in case of a lack of waste, heat is advised to dry SCG in a diversified system and organising a system of collecting material with $10-12 \%$ humidity.

\section{CONCLUSIONS}

The paper examined possibilities of using spent coffee ground as an additive to alternative solid fuels. The additive is worth considering due to a number of factors. First of all, no additional investments are required while applying SCG as a biofuel component. Small companies producing briquettes and possessing devices to make them can successfully use SCG as an additive to wood chips, therefore, contributing to limiting biodegradable waste sent to landfill sites and causing an increase in calorific values of produced briquettes. Potential energy contained in SCG produced in Poland is about 2.3PJ which is $1.16 \%$ energy contained in biomass produced in Poland. Briquettes produced with SCG additions have higher calorific values in comparison to briquettes made from pure wood and it is compara- ble to hard bituminous coal of poor quality. It all contributes to an increase of profitability by using it as an energy source. However, SCG added in an amount of $25 \%$ resulted in significantly lower hardness of the briquettes which prevents their storage in high heaps.

\section{REFERENCES}

1. Alakangas E., Valtanen J., Levlin J.E. 2006. CEN technical specification for solid biofuels - Fuel specification and classes. Biomass Bioenerg, 30, 908-914.

2. Boonamnuayvitaya V., Saeung S., Tanthapanichakoon W. 2005. Preparation of activated carbons from coffee residue for the adsorption of formaldehyde. Sep Purif Technol, 42, 159-168.

3. Chau J., Sowlati T., Sokhansanj S., Preto F., Melin S., Bi X. 2009. Economic sensitivity of wood biomass utilization for greenhouse heating application. Appl Energ 86, 616-621.

4. Ciesielczuk T., Poluszyńska J., Sporek M. 2014. Potential uses for solid biofuels from non-food crops. Proceedings of ECOpole, 2(8), 363-368, DOI: 10.2429/proc.2014.8(2)044 2014;8(2).

5. Couto R.M., Fernandes J., da Silva M.D.R.G., Simoes PC. 2009. Supercritical fluid extraction of lipids from spent coffee grounds. J Supercrit Fluid 51, 159-166.

6. Domanska D., Zacharz T. 2008. Biomass wastes as source of alternative energy. Archives of Environmental Protection, 34, 39-54.

7. Dudek H. 2005. Analysis of coffee consumption in 
Poland. [In:] Efficiency of marketing management. Warsaw, 28, 215-223 (in Polish).

8. Erlich C., Bjornbom E., Bolado D., Giner M., Fransson TH. 2006. Pyrolysis and gasification of pellets from sugar cane bagasse and Wood. Fuel, $85,1535-1540$.

9. Gołuchowska B, Sławiński J., Markowski G. 2015. Biomass utilization as a renevable energy source in polish power industry - current status and perspectives. Journal of Ecological Engineering, 16(3), 143-154.

10. Hasan M., Salam A., Shafiqul Alam A.M. 2009. Identification and characterization of trace metals in black solid materials deposited from biomass burning at the cooking stoves in Bangladesh. Biomass Bioenerg., 33, 1376-1380.

11. Heinimo J., Junginger M. 2009. Production and trading of biomass for energy - An overview of the global status. Biomass Bioenerg. 33, 1310-1320.

12. Kaliyan N., Morey R.V. 2010. Natural binders and solid bridge type binding mechanisms in briquettes and pellets made from corn stover and switchgrass. Bioresource Technol. 101, 1082-1090.

13. Kautz M., Hansen U. 2007. The externally-fired gas-turbine (EFGT-Cycle) for decentralized use of biomass. Appl Energ 84, 795-805.

14. Kondamudi N, Mohapatra SK, Misra M. 2008. Spent Coffee Grounds as a Versatile Source of Green Energy. J. Agr. Food Chem., 56(24), 11757-11760.

15. Kordylewski W. 1999. Burning and Fuels. Oficyna Wydawnicza Politechniki Wrocławskiej, Wrocław (in Polish).

16. Masek O., Konno M., Hosokai S., Sonoyama N., Norinaga K., Hayashi J.I. 2008. A study on pyrolytic gasification of coffee grounds and implications to allothermal gasification. Biomass Bioenerg., 32, 78-89.

17. Mazzoli-Rocha F., Bichara Magalhaes C., Malm O., Nascimento Saldiva PH., Zin WA., Souza Faffe D. 2008. Comparative respiratory toxicity of particles produced by traffic and sugar cane burning. Environ. Res., 108, 35-41.

18. Obernberger I., Thek G. 2004. Physical characterisation and chemical composition of densified bio- mass fuels with regard to their combustion behaviour. Biomass Bioenerg., 27, 653-669.

19. Oliveira L.S., Franca A.S., Alves T.M., Rocha S.D.F. 2008. Evaluation of untreated coffee husks as potential biosorbents for treatment of dye contaminated Walters. J. Hazard. Mater., 155, 507-512.

20. Olsson M., Kjallstrand J. 2004. Emissions from burning of softwood pellets. Biomass Bioenerg., 27, 607-611.

21. Orozco A.L., Perez M.I., Guevara O., Rodriguez J., Hernandez M., Gonzalez-Vila F.J., Polvillo O., Arias M.E. 2008. Biotechnological enhancement of coffee pulp residues by solid-state fermentation with Streptomyces. Py-GC/MS analysis. J. Anal. Appl. Pyrolysis, 81, 247-252.

22. Purohit P., Tripathi A.K., Kandpal T.C. 2006. Energetics of coal substitution by briquettes of agricultural residues. Energy, 31, 1321-1331.

23. Shih S.I., Lee W.J., Lin L.F., Huang J.Y., Su J.W., Chang-Chien G.P. 2008. Significance of biomass open burning on the levels of polychlorinated dibenzo- $p$-dioxins and dibenzofurans in the ambient air. J. Hazard. Mater., 153, 276-284.

24. Singh R.N. 2004. Equilibrium moisture content of biomass briquettes. Biomass and Bioenergy 26, 251-253.

25. Walaszek J., Dudzinska M.R. 2007. Effect of alternative fuels co-incineration on NOx emission from cement production. [In:] Pawlowski, Dudzinska \& Pawłowski (Eds) Environmental Engineering, Taylor \& Francis Group, London 359-363.

26. Wang Q., Shao M., Liu Y., William K., Paul G., Li X., Liu Y., Lu S. 2007. Impact of biomass burning on urban air quality estimated by organic tracers: Guangzhou and Beijing as cases. Atmos. Environ., $41,8380-8390$.

27. Wang Z., Bi X., Sheng G., Fu J. 2009. Characterization of organic compounds and molecular tracers from biomass burning smoke in South China I; Broad-leaf trees and shrubs. Atmos. Environ., 43, 3096-3102.

28. Yan X., Ohara T., Akimoto H. 2006. Bottom-up estimate of biomass burning in mainland China. Atmos. Environ., 40, 5262-5273. 